\title{
Obstacle Avoidance Increases Asymmetry of Crossing Step in Individuals With Parkinson's Disease and Neurologically Healthy Individuals
}

Fabio Augusto Barbieri, Lucas Simieli, Diego Orcioli-Silva, André Macari Baptista, Mayara Borkowske Pestana, Victor Spiandor Beretta, Paulo Cezar Rocha dos Santos \& Lilian Teresa Bucken Gobbi

To cite this article: Fabio Augusto Barbieri, Lucas Simieli, Diego Orcioli-Silva, André Macari Baptista, Mayara Borkowske Pestana, Victor Spiandor Beretta, Paulo Cezar Rocha dos Santos \& Lilian Teresa Bucken Gobbi (2018) Obstacle Avoidance Increases Asymmetry of Crossing Step in Individuals With Parkinson's Disease and Neurologically Healthy Individuals, Journal of Motor Behavior, 50:1, 17-25, DOI: 10.1080/00222895.2016.1271303

To link to this article: https://doi.org/10.1080/00222895.2016.1271303

曲 Published online: 02 Mar 2017.

Submit your article to this journal $\widetilde{ }$

Щ Article views: 101

View Crossmark data ¿

Citing articles: 1 View citing articles $\square$ 


\title{
Obstacle Avoidance Increases Asymmetry of Crossing Step in Individuals With Parkinson's Disease and Neurologically Healthy Individuals
}

\author{
Fabio Augusto Barbieri ${ }^{1,2}$, Lucas Simieli ${ }^{2}$, Diego Orcioli-Silva ${ }^{2}$, André Macari Baptista $^{1,2}$, \\ Mayara Borkowske Pestana', Victor Spiandor Beretta ${ }^{2}$, Paulo Cezar Rocha dos Santos ${ }^{2}$, \\ Lilian Teresa Bucken Gobbi ${ }^{2}$ \\ ${ }^{1}$ Human Movement Research Laboratory (MOVI-LAB), Faculty of Science, Department of Physical Education, Universidade \\ Estadual Paulista-UNESP, Bauru, Brazil. ${ }^{2}$ Posture and Gait Studies Laboratory (LEPLO), Bioscience Institute, Department of \\ Physical Education, Universidade Estadual Paulista-UNESP, Rio Claro, Brazil.
}

\begin{abstract}
The authors' aim was to investigate gait asymmetry of crossing step during obstacle avoidance while walking in people with Parkinson's disease (PD) under and without the effects of dopaminergic medication. Thirteen individuals with PD and 13 neurologically healthy individuals performed 5 trials of unobstructed gait and 10 trials of obstacle crossing during gait (5 trials with each leg) and spatiotemporal parameters were analyzed. Obstacle crossing increased step duration of the crossing step for the most-affected or nondominant limb compared to the crossing step with the least-affected or dominant limb. Individuals with PD without the effects of medication increased step duration for the step with the least-affected limb compared to the step with the most-affected limb during obstacle crossing.
\end{abstract}

Keywords: asymmetry, dopaminergic medication, gait, obstacle avoidance

G ait is considered symmetric in neurologically healthy people. However, asymmetry begins to occur with aging (Sadeghi, Allard, Prince, \& Labelle, 2000) and could be indicative of a neurodegenerative disease (Plotnik, Giladi, Balash, Peretz, \& Hausdorff, 2005), such as Parkinson's disease (PD). However, the mechanisms that cause gait asymmetry in people with PD are not well known, especially when related to obstacle avoidance during walking and dopaminergic medication response. Gait asymmetries in PD reflect an asymmetric depletion of dopamine in the substantia nigra between the cerebral hemispheres (Booij et al., 1997; Kaasinen et al., 2001). This results in asymmetrical deregulation of the striatum, leading to further asymmetrical dysfunction of multiple circuits involving the basal ganglia and cortical regions (JohnsonFrey, 2004; Middleton \& Strick, 2000). Asymmetry reflects mediolateral imbalance, instability, and, hence, a predisposition to falls (Galna, Peters, Murphy, \& Morris, 2009; Vitório, Pieruccini-Faria, Stella, Gobbi, \& Gobbi, 2010).

Unobstructed walking in individuals with PD is asymmetric. Previous studies have indicated that swing time and gait variability are the most asymmetrical parameters in people with PD compared to neurologically healthy individuals, which are related to freezing episodes, falls, and decreased executive function (Baltadjieva, Giladi, Gruendlinger, Peretz, \& Hausdorff, 2006; Plotnik et al., 2005; Plotnik, Giladi, \& Hausdorff, 2009). However, step length and ground reaction forces (Nanhoe-Mahabier et al., 2011) do not seem to be asymmetrical parameters in unobstructed walking for people with PD. In addition, dopaminergic medication seems to decrease gait asymmetry in people with PD during unobstructed walking (Frazzitta, Pezzoli, Bertotti, \& Maestri, 2013; Lewek, Poole, Johnson, Halawa, \& Huang, 2010; Plotnik et al., 2005). Despite important findings in previous studies regarding gait asymmetry during unobstructed walking, the analysis of asymmetry during complex gait tasks, such as obstacle avoidance, which is performed daily by this population (Vitório et al., 2010), has been neglected.

Obstacle avoidance involves complex circuitry, such as the parietal and motor cortex, the lateral cerebellum and pontine gray nuclei (Snijders et al., 2010), which seems to represent a more complex walking task. An increase in complexity requires finely tuned co-ordination to step over the obstacle (Chou, Kaufmann, Brey, \& Draganich, 2001; Patla \& Prentice, 1995). In addition, a successful and safe obstacle crossing requires efficient (spatial and temporal parameters) step avoidance (Chou et al., 2001; Patla \& Prentice, 1995), which is considered the main step during obstacle crossing while walking (Patla \& Prentice, 1995). Previous research has indicated that obstacle crossing during walking increases gait impairment in people with PD, mainly the hypometry and bradykinesia (i.e., reduced step length and step velocity; Galna et al., 2009; PierucciniFaria et al., 2006; Vitório et al., 2013; Vitório et al., 2010), but does not indicate whether the effects on gait asymmetry are exacerbated in this population during obstacle avoidance. Therefore, the main question of this study is: Does obstacle crossing during gait increase gait asymmetry in people with PD? In addition, clarifications regarding dopaminergic therapy during obstacle crossing are necessary to improve the understanding of how dopaminergic medication affects gait asymmetry.

Correspondence address: Fabio Augusto Barbieri, Human Movement Research Laboratory (MOVI-LAB), Faculty of Science, Department of Physical Education, Universidade Estadual Paulista - UNESP - FC - Bauru, Av. Eng. Luiz Edmundo Carrijo Coube, 14-01, CEP: 17033-360_Bauru, SP - Brazil. e-mail: barbieri@fc.unesp.br 
Therefore, the aim of this study was to investigate gait asymmetry of crossing step during obstacle avoidance while walking in people with PD under and without the effects of dopaminergic medication. This is the first study to investigate the influence of obstacle crossing on gait asymmetry in individuals with PD. The hypothesis of this study was that gait asymmetry would increase in the crossing step during obstacle avoidance compared to unobstructed walking, due to the increase in motor demands, which are impaired in this population (Galna et al., 2009; Pieruccini-Faria et al., 2006; Vitório et al., 2013; Vitório et al., 2010). In addition, we hypothesized that dopaminergic medication would regulate (decrease) the gait asymmetry in the crossing step, as asymmetry is apparently greater in patients with motor response fluctuations, which is a characteristic of people with PD in the OFF dopaminergic medication state (Plotnik et al., 2005).

\section{Methods}

Thirteen individuals with PD (PD group) and 13 neurologically healthy individuals (control group) participated in this study. The individuals with PD were recruited, at least 4 months after diagnosis, from the Physical Activity Program for Patients with PD (PROPARKI Group) at UNESPRio Claro (Brazil). The control group was recruited from the Physical Activity Program for the Third Age (PROFIT Group) at UNESP-Rio Claro (Brazil). The groups were matched by age, height, and weight.

The individuals with PD were referred to the present study by local neurologists. Briefly, a diagnosis of idiopathic PD was confirmed by a specialist according to the UK Parkinson's Disease Brain bank criteria (Gibb \& Less, 1988). The exclusion criteria comprised (a) suspected parkinsonism before the onset of the study, (b) significant memory impairment (defined as Mini-Mental State Examination score < 24; O. P. Almeida, 1998), (c) presentation of other parkinsonism syndromes, (d) not presenting independent living in the community, (e) not able to walk without the use of any aids, and (f) disorders that impaired locomotion. In addition, for people with PD, individuals were included in the study if their stage on the Hoehn and Yahr (H\&Y) scale (Hoehn \& Yahr, 1967) was $\leq 3$ and they were under dopaminergic medication treatment. The study was approved by the local ethics committee and all participants gave informed consent (\#0227/2013).

The individuals with PD were evaluated under two conditions: (a) OFF medication state, which was after a minimum of $12 \mathrm{hr}$ without dopaminergic medication, and in addition, if the individuals had taken dopaminergic agonist medication, they were evaluated after a minimum of $24 \mathrm{hr}$ without medication; (b) and ON (optimal) medication state which was $1 \mathrm{hr}$ after medication intake. The optimal medication state was confirmed with the participant (selfreported) and by assessing the items of the Unified Parkinson's Disease Rating Scale (UPDRS) III. The levodopa equivalent daily dose was calculated according to established methods (Tomlinson et al., 2010). The control group performed the evaluation once.

\section{Clinical Evaluation}

A movement disorder specialist performed participant interviews to characterize the PD and control groups, especially the side on which the symptoms were occurring. Next he performed a clinical assessment of the individuals with PD to determine the stage of the disease in each patient and to test them on the motor section of the UPDRS (Fahn \& Elton, 1987) and H\&Y scale. In addition, cognitive impairments in both groups were evaluated using the MiniMental State Examination. The UPDRS and H\&Y scale were evaluated in the $\mathrm{ON}$ and OFF dopaminergic state. The cognitive status was evaluated only in the ON medication state in people with PD to avoid learning effects.

\section{Footedness and Appendicular Asymmetry}

Footedness was assessed in the control group and PD group by asking all participants to kick a ball to hit a target. The limb that each individual chose to kick the ball was considered the preferred limb. For patients with PD, motor UPDRS items 20-23 and 25-26 were used to assess appendicular asymmetry (Stewart et al., 2009). The most severely affected limb (most-affected limb) was determined by finding the difference between the scores for the right and left limbs in the aforementioned UPDRS items. When this calculation resulted in a positive value, the right limb was considered the more severely affected, but when negative values were obtained, this indicated that the left limb was more severely affected. The other limb was defined as least-affected limb.

\section{Walking Task}

The walking was evaluated in the $\mathrm{ON}$ and OFF dopaminergic state. The people with PD remained seated during one hour after medicine intake to avoid fatigue effects. In addition, all participants were instructed to report some tiredness during the experiment and we gave a rest when was necessary. Participants performed five trials of unobstructed gait and ten trials of obstacle crossing during gait (five crossing trials with each leg). The trial order was randomly defined. Participants were instructed to walk over a $10 \mathrm{~m}$ wooden pathway, which was covered with a black rubber carpet ( $3 \mathrm{~mm}$ thick), at a self-selected speed. In the obstacle crossing trials, the participants were also instructed to avoid contact with the obstacle $(15 \mathrm{~cm}$ high, $80 \mathrm{~cm}$ wide and $2 \mathrm{~cm}$ thick), which was positioned in the middle of the pathway. The starting point ( $\sim 5 \mathrm{~m}$ from the obstacle) was adjusted according to the leg that the participant needed to cross the obstacle and to ensure that at least two strides (walking acceleration phase) were completed prior to obstacle crossing. 
Acquisition of kinematic gait parameters was accomplished with GAITRite (CIR System, Clifton, NJ), using a sample rate of 200 samples/s. The midpathway stride (one step with the right limb and one step with the left limb; see Figure 1a) was analyzed for unobstructed walking. The steps were analyzed considering footedness. The crossing step (step when leading limb crossed the obstacle) was analyzed for obstacle avoidance trials (Figures $1 \mathrm{~b}$ and 1c). The step length, duration (duration of both stance and swing phase), width and velocity, limb swing duration (percentage of step duration), and double support duration (percentage of step duration) were calculated for each step for unobstructed and obstructed walking. The average of trials was calculated for each participant considering walking (unobstructed and obstacle walking) and limb (most/nondominant and least/dominant affected limb). To analyze gait asymmetry, the steps (average of trials for each participant) with the most and least-affected limb (according to the UPDRS items), for people with PD, and the dominant and nondominant limb (according to footedness test), for the control group, were compared considering walking. For example, average of step length from step with leastaffected/dominant limb (i.e., left step in Figure 1a) and most-affected/nondominant limb in unobstructed walking (i.e., right step in Figure 1a) were compared with average of step length from crossing step with least-affected/ dominant limb (i.e., crossing left step in Figure 1c) and most-affected/nondominant limb (i.e., crossing right step in Figure $1 b$ ) in obstacle avoidance walking (it was considered group). Additionally, the intertrial variability of these parameters using a coefficient of variation was calculated (Hausdorff, Rios, \& Edelberg, 2001). Finally, the symmetric index (Herzog, Nigg, Read, \& Olsson, 1989), considering the average of each participant in each type of walking (absolute values), was calculated between the most-affected and least-affected limbs for people with PD and the dominant and nondominant limbs for the control group (Beretta et al., 2015; Barbieri et al., 2016). However, we were interested only in the magnitude of symmetry, and did not consider the values of positive or negative (Beretta et al., 2015; Barbieri et al., 2016). For individuals with PD the medication state (ON and OFF state) was also considered.

symmetric index

$$
\begin{aligned}
= & {\left[\frac{\text { value of least affected } \operatorname{limb}-\text { value of most affected limb }}{(\text { value of least affected limb }+ \text { value of most affected limb })}\right] } \\
& \times 100 \%
\end{aligned}
$$

This is an example for people with PD. For control group was considered least-affected limbs as dominant limb and most-affected limb as nondominant limb. The symmetric

a)

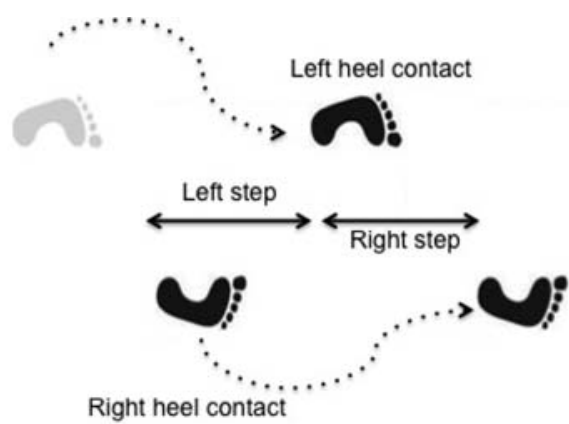

b)

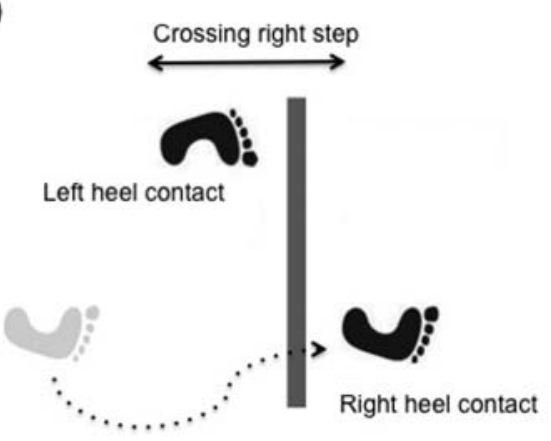

c)

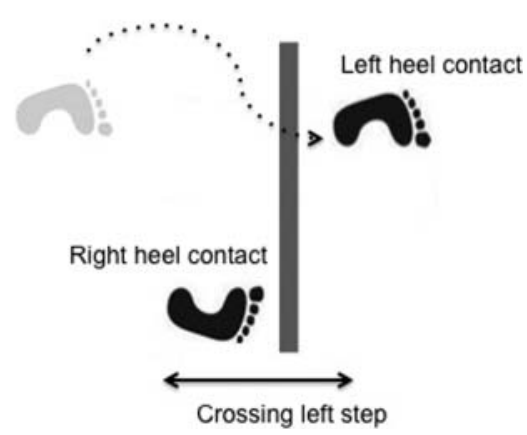

FIGURE 1. A top view of the analyzed steps in the study for unobstructed walking (a), crossing right step (b) and crossing left step (c). The crossing step was analyzed when the leading limb crosses the obstacle. Left and right step or crossing step was titled leastor most-affected step, for PD group, or dominant and nondominant step, for control group, according to appendicular asymmetry and footedness, respectively. 
index was calculated separately for each gait parameter. A value of zero for index indicates that there is no difference between sides. Higher symmetric index values indicated higher asymmetry of the individuals.

\section{Statistical Analysis}

The analysis with $\mathrm{G}^{*}$ Power software (version 3.1.2; Franz Faul, University of Kiel, Kiel, Germany) showed that a sample size of at least 24 individuals (12 in each group) was needed for an $80 \%$ probability to detect a difference of $20 \%$ between the two groups for the primary outcome with a type I error of 0.05 , based on previously published data (Gibb \& Lees, 1988; Pieruccini-Faria et al., 2006; Vitório et al., 2013). For cognitive status, unrelated sample Student $t$ tests were employed for comparisons between groups (control group by PD group). In addition, clinical variables were compared between people with $\mathrm{PD}$ in the $\mathrm{ON}$ and $\mathrm{OFF}$ dopaminergic state using related sample student t-tests. Gait parameters (mean and variability) were analyzed with a multivariate analysis of variance (MANOVA; Group [control, PD in ON stage] $\times$ Walking [unobstructed, obstacle trials] $\times$ Limb [least/dominant, most/nondominant affected limbs]), with walking and limb as repeated measures. A separate analysis of individuals with PD for gait parameters was conducted with dopaminergic status in a within-subject design with $\mathrm{ON} / \mathrm{OFF}$ as a repeated-measure. In addition, the effect size (partial eta squared) was measured for each

TABLE 1. Means and standard deviations of characteristics and clinical variables of the PD and control groups

\begin{tabular}{|c|c|c|}
\hline & PD group & Control group \\
\hline Age (years) & $70.33 \pm 6.02$ & $70.77 \pm 7.56$ \\
\hline Height (m) & $1.62 \pm 0.08$ & $1.60 \pm 0.06$ \\
\hline Body mass (kg) & $68.20 \pm 12.48$ & $70.15 \pm 10.32$ \\
\hline MMSE (points) & $26.85 \pm 1.82$ & $28.38 \pm 2.10$ \\
\hline $\begin{array}{l}\text { UPDRS III OFF } \\
\text { (score) }\end{array}$ & $29.08 \pm 7.75$ & - \\
\hline UPDRS III ON (score) & $24.08 \pm 6.18$ & - \\
\hline H\&Y OFF (score) & $2.12 \pm 0.30$ & - \\
\hline H\&Y ON (score) & $2.08 \pm 0.34$ & - \\
\hline LEDD (mg/day) & $492.79 \pm 322.28$ & - \\
\hline \multicolumn{3}{|l|}{$\begin{array}{l}\text { Anti-Parkinson's } \\
\text { medication }\end{array}$} \\
\hline Levodopa $(n, \%)$ & $10,76.9 \%$ & \\
\hline $\begin{array}{l}\text { Dopamine agonist ( } n \text {, } \\
\% \text { ) }\end{array}$ & $5,38.6 \%$ & \\
\hline $\begin{array}{l}\text { MAOB inhibitor ( } n \text {, } \\
\% \text { ) }\end{array}$ & $2,15.5 \%$ & \\
\hline \multicolumn{3}{|c|}{$\begin{array}{l}\text { The levodopa equivalent daily dosage (LEDD) and number of indi- } \\
\text { viduals with Parkinson's disease (PD) that take each PD medication } \\
\text { are also reported in the table. H\&Y = Hoehn \& Yahr Scale; MMSE } \\
\text { = Mini-Mental State Examination; MAOB = monoamine oxidase } \\
\text { B; UPDRS = Unified Parkinson's Disease Rating Scale. }\end{array}$} \\
\hline
\end{tabular}

statistical analysis. All significant interactions were subjected to Tukey's post hoc analysis ( $\alpha=.05$; SPSS 15.0).

\section{Results}

The group characteristics, clinical variables and dopaminergic medication dosage are presented in Table 1. All participants of this study (PD group and control group) were right preferred limb. In addition, three individuals with PD presented the right limb as the most-affected limb while 10 individuals had the left limb as the most-affected limb. The PD group and control group presented similar cognitive status, $t(24)=1.95, p<.07$. However, the dopaminergic medication state influenced performance in the UPDRS-motor, in which individuals with PD under the effects of medication presented better performance, $t(12)=5.39, p<.001$, but no significant difference for score in the H\&Yscale, $t$ $(12)=-0.99, p<.33$.

For gait parameters, the MANOVAs revealed main effect of group, walking, limb, and group by limb and walking by limb interactions (Table 2 and 4). For group, the PD group demonstrated shorter step length, reduced speed and longer step duration than the control group. For walking, crossing step during obstacle avoidance presented increased step length, step duration, limb swing duration, and variability of double support duration, and decreased step velocity, double support duration, and variability of limb swing duration compared to unobstructed walking. In addition, crossing step during obstacle avoidance showed greater variability of step duration compared to step with unobstructed walking. Finally, both groups demonstrated a higher symmetric index for step duration $(p<.003)$ during obstacle crossing while walking compared to unobstructed walking (Table 3). For limb, the step with the mostaffected/nondominant limb increased step duration and double support duration and decreased limb swing duration compared to the step with the least-affected/dominant limb.

In the group by limb interaction (Tables 2 and 4), the control group was faster (step velocity) than the PD group in both limbs. For walking by limb (Tables 2 and 4), obstacle crossing increased step duration of both crossing step limbs (least/dominant and most/nondominant limbs) compared to step with unobstructed walking and increased step duration of the step with the most-affected/nondominant limb compared to the step with the least-affected/dominant limb.

When considering the effects of dopaminergic medication (PD groups in ON by OFF dopaminergic medication state), the MANOVAs indicated main effects of medication, walking, and limb. In addition, the statistical analysis showed medication by limb, medication by walking, and medication by limb by walking interactions (Tables 2 and 4). Dopaminergic medication increased step length, step velocity, and limb swing duration; and decreased double support duration and step length variability. During obstacle avoidance, crossing step showed increased step length, 
TABLE 2. Mean \pm standard deviation and variability \pm standard deviation of the walking parameters for the PD group (ON and OFF states) and the control group

\begin{tabular}{|c|c|c|c|c|c|c|c|}
\hline & & \multicolumn{2}{|c|}{ Control group } & \multicolumn{2}{|c|}{ PD group ON state } & \multicolumn{2}{|c|}{ PD group OFF state } \\
\hline & & Dominant limb & $\begin{array}{l}\text { Nondominant } \\
\text { limb }\end{array}$ & $\begin{array}{l}\text { Least-affected } \\
\text { limb }\end{array}$ & $\begin{array}{c}\text { Most-affected } \\
\text { limb }\end{array}$ & $\begin{array}{l}\text { Least-affected } \\
\operatorname{limb}\end{array}$ & $\begin{array}{c}\text { Most-affected } \\
\operatorname{limb}\end{array}$ \\
\hline \multirow[t]{2}{*}{ Step length $(\mathrm{cm})$} & UNO & $63.57 \pm 4.25$ & $62.88 \pm 5.84$ & $57.96 \pm 6.77$ & $59.00 \pm 7.10$ & $55.80 \pm 6.93$ & $55.86 \pm 7.16$ \\
\hline & OBS & $65.23 \pm 6.89$ & $65.90 \pm 6.43$ & $63.42 \pm 6.06$ & $64.14 \pm 6.73$ & $63.08 \pm 8.70$ & $62.12 \pm 8.28$ \\
\hline \multirow[t]{2}{*}{ Step duration (s) } & UNO & $0.50 \pm 0.05$ & $0.51 \pm 0.05$ & $0.54 \pm 0.06$ & $0.54 \pm 0.05$ & $0.55 \pm 0.06$ & $0.54 \pm 0.05$ \\
\hline & OBS & $0.65 \pm 0.07$ & $0.68 \pm 0.07$ & $0.74 \pm 0.09$ & $0.75 \pm 0.08$ & $0.78 \pm 0.09$ & $0.75 \pm 0.08$ \\
\hline \multirow[t]{2}{*}{ Step width $(\mathrm{cm})$} & UNO & $10.53 \pm 2.24$ & $10.86 \pm 2.87$ & $10.55 \pm 3.51$ & $11.00 \pm 3.62$ & $11.53 \pm 3.38$ & $11.85 \pm 3.69$ \\
\hline & OBS & $10.63 \pm 1.89$ & $11.21 \pm 2.13$ & $13.08 \pm 4.69$ & $13.10 \pm 3.77$ & $13.69 \pm 4.90$ & $12.61 \pm 4.13$ \\
\hline \multirow[t]{2}{*}{ Step velocity $(\mathrm{cm} / \mathrm{s})$} & UNO & $126.16 \pm 10.85$ & $123.27 \pm 11.97$ & $108.57 \pm 18.62$ & $110.69 \pm 20.33$ & $102.77 \pm 15.60$ & $103.55 \pm 16.71$ \\
\hline & OBS & $101.71 \pm 11.70$ & $98.96 \pm 13.78$ & $87.01 \pm 13.80$ & $87.14 \pm 15.98$ & $81.92 \pm 11.23$ & $83.19 \pm 12.33$ \\
\hline \multirow[t]{2}{*}{ Limb swing (\%) } & UNO & $76.72 \pm 2.05$ & $75.55 \pm 1.88$ & $75.38 \pm 2.97$ & $73.90 \pm 1.82$ & $73.94 \pm 2.84$ & $72.67 \pm 2.35$ \\
\hline & OBS & $84.37 \pm 2.64$ & $83.79 \pm 1.94$ & $84.10 \pm 2.40$ & $83.62 \pm 2.28$ & $83.43 \pm 3.18$ & $82.72 \pm 2.68$ \\
\hline \multirow[t]{3}{*}{ Double support (\%) } & UNO & $23.28 \pm 2.05$ & $24.44 \pm 1.88$ & $24.61 \pm 2.91$ & $26.10 \pm 1.82$ & $26.07 \pm 2.63$ & $27.28 \pm 2.27$ \\
\hline & OBS & $15.21 \pm 2.43$ & $15.94 \pm 1.90$ & $15.90 \pm 2.40$ & $16.42 \pm 2.18$ & $16.60 \pm 3.09$ & $17.28 \pm 2.68$ \\
\hline & \multicolumn{7}{|c|}{ Variability } \\
\hline \multirow[t]{2}{*}{ Step length (\%) } & UNO & $3.03 \pm 1.25$ & $2.87 \pm 1.65$ & $3.73 \pm 2.35$ & $3.76 \pm 1.82$ & $2.93 \pm 1.80$ & $3.76 \pm 1.44$ \\
\hline & OBS & $4.17 \pm 2.05$ & $3.55 \pm 1.73$ & $3.38 \pm 1.86$ & $3.30 \pm 2.02$ & $5.17 \pm 3.55$ & $5.84 \pm 2.67$ \\
\hline \multirow[t]{2}{*}{ Step duration $(\%)$} & UNO & $2.66 \pm 1.60$ & $2.34 \pm 0.99$ & $2.56 \pm 1.09$ & $2.20 \pm 0.78$ & $3.13 \pm 1.58$ & $2.63 \pm 0.78$ \\
\hline & OBS & $3.61 \pm 0.93$ & $4.23 \pm 1.84$ & $4.36 \pm 2.63$ & $4.91 \pm 1.84$ & $3.69 \pm 1.69$ & $4.94 \pm 2.28$ \\
\hline \multirow[t]{2}{*}{ Step width $(\%)$} & UNO & $16.61 \pm 7.13$ & $15.48 \pm 7.14$ & $15.13 \pm 5.18$ & $21.33 \pm 8.24$ & $16.55 \pm 4.57$ & $14.61 \pm 8.04$ \\
\hline & OBS & $23.34 \pm 9.48$ & $21.69 \pm 11.88$ & $22.63 \pm 9.23$ & $21.45 \pm 11.03$ & $16.68 \pm 11.21$ & $21.86 \pm 11.72$ \\
\hline \multirow[t]{2}{*}{ Step velocity (\%) } & UNO & $3.95 \pm 1.70$ & $3.57 \pm 2.28$ & $4.89 \pm 2.86$ & $4.43 \pm 1.83$ & $4.24 \pm 1.57$ & $5.24 \pm 2.07$ \\
\hline & OBS & $5.28 \pm 2.22$ & $5.06 \pm 2.69$ & $5.51 \pm 3.23$ & $5.54 \pm 2.44$ & $6.28 \pm 4.00$ & $7.27 \pm 3.51$ \\
\hline \multirow[t]{2}{*}{ Limb swing (\%) } & UNO & $1.74 \pm 0.66$ & $2.23 \pm 1.55$ & $2.15 \pm 0.81$ & $2.65 \pm 1.27$ & $2.26 \pm 1.138$ & $2.51 \pm 0.80$ \\
\hline & OBS & $1.49 \pm 0.75$ & $1.92 \pm 2.41$ & $1.40 \pm 0.58$ & $1.60 \pm 0.55$ & $1.72 \pm 0.81$ & $1.86 \pm 0.79$ \\
\hline \multirow[t]{2}{*}{ Double support (\%) } & UNO & $5.46 \pm 2.28$ & $4.97 \pm 1.90$ & $6.56 \pm 2.14$ & $7.23 \pm 3.21$ & $5.46 \pm 2.56$ & $6.54 \pm 1.91$ \\
\hline & OBS & $8.23 \pm 3.99$ & $6.66 \pm 3.02$ & $7.49 \pm 3.02$ & $8.13 \pm 3.15$ & $8.34 \pm 3.19$ & $9.34 \pm 4.59$ \\
\hline
\end{tabular}

$\mathrm{OBS}=$ walking with obstacle crossing; $\mathrm{PD}=$ Parkinson's disease; $\mathrm{UNO}=$ unobstructed walking.

step duration, limb swing duration, and step velocity, whereas double support duration was decreased in comparison to step with unobstructed walking. In addition, there was increased variability in step duration, step velocity and double support duration and decreased variability in limb swing duration in the crossing step during obstacle avoidance. Furthermore, the symmetry index indicated greater asymmetry for step duration $(p<.02)$ during obstacle crossing. In both conditions (unobstructed and obstacle walking), the step with the most-affected limb presented shorter limb swing duration and longer double support duration compared to the step with the least-affected limb.

Medication by walking interaction (Tables 2 and 4) showed decreased variability in step length under dopaminergic medication effects during crossing step of obstacle avoidance. In addition, when the individuals with PD were in the OFF dopaminergic state, variability in step length and double support duration increased during crossing step of obstacle avoidance compared to step with unobstructed walking.

Medication by limb interaction (Tables 2 and 4) indicated that dopaminergic medication increased step length of the step with the most-affected and least-affected limbs, respectively. In addition, there was decreased step duration of the step with the least-affected limb in the ON medication state. Finally, when the PD group was in the OFF dopaminergic state, the step with the least-affected limb presented longer step duration compared to the step with the most-affected limb.

Medication by limb by walking interaction (Figure 2) revealed that dopaminergic medication decreased step duration and increased step width variability of the crossing step during obstacle avoidance with the least-affected limb. In addition, in unobstructed walking, dopaminergic medication increased step width variability of the step with the most-affected limb compared to the step with the leastaffected limb. However, the PD group without the effects of dopaminergic medication demonstrated increased step duration for the crossing step during obstacle avoidance with the least-affected limb compared to the crossing step with the most-affected limb, and decreased variability of step width for the step with the most-affected limb compared to the $\mathrm{ON}$ dopaminergic medication state.

\section{Discussion}

The hypotheses of this study were that gait asymmetry would be increased in the crossing step during obstacle avoidance compared to unobstructed walking and that 
TABLE 3. Means and standard deviations of the symmetric index of walking parameters for the PD group (ON and OFF state) and the control group

\begin{tabular}{|c|c|c|c|c|}
\hline & & Control group & $\begin{array}{l}\text { PD group } \\
\text { ON state }\end{array}$ & $\begin{array}{l}\text { PD group } \\
\text { OFF state }\end{array}$ \\
\hline \multirow[t]{2}{*}{ Step length $(\%)$} & UNO & $1.94 \pm 2.02$ & $2.30 \pm 2.09$ & $1.96 \pm 1.41$ \\
\hline & OBS & $2.11 \pm 1.75$ & $1.88 \pm 1.45$ & $1.84 \pm 1.48$ \\
\hline \multirow[t]{2}{*}{ Step duration $(\%)$} & UNO & $1.07 \pm 0.86$ & $1.23 \pm 0.77$ & $0.96 \pm 0.66$ \\
\hline & OBS & $2.52 \pm 1.84$ & $2.30 \pm 1.67$ & $2.23 \pm 1.94$ \\
\hline \multirow[t]{2}{*}{ Step width (\%) } & UNO & $3.82 \pm 3.10$ & $6.39 \pm 6.84$ & $4.14 \pm 3.29$ \\
\hline & OBS & $7.57 \pm 5.85$ & $5.94 \pm 5.80$ & $8.07 \pm 9.66$ \\
\hline \multirow[t]{2}{*}{ Step velocity (\%) } & UNO & $1.89 \pm 1.80$ & $2.60 \pm 1.96$ & $2.09 \pm 1.81$ \\
\hline & OBS & $2.77 \pm 1.60$ & $2.20 \pm 1.55$ & $1.73 \pm 1.52$ \\
\hline \multirow[t]{2}{*}{ Limb swing (\%) } & UNO & $0.91 \pm 0.80$ & $1.44 \pm 1.57$ & $1.61 \pm 1.03$ \\
\hline & OBS & $0.84 \pm 0.51$ & $0.52 \pm 0.63$ & $1.03 \pm 1.19$ \\
\hline \multirow[t]{2}{*}{ Double support (\%) } & UNO & $2.95 \pm 2.69$ & $4.33 \pm 4.74$ & $4.38 \pm 3.23$ \\
\hline & OBS & $5.10 \pm 4.10$ & $2.96 \pm 3.59$ & $5.21 \pm 5.90$ \\
\hline
\end{tabular}

dopaminergic medication would regulate (decrease) the gait asymmetry. Our findings confirmed our hypothesis that obstacle crossing (leading limb crossing step) increased gait asymmetry of crossing step compared to unobstructed walking. However, both the PD group and control group presented similar asymmetrical behavior during obstacle crossing while walking. In addition, as we expected, dopaminergic medication decreased gait asymmetry, mainly for obstacle crossing, which corroborates with previous studies (Lewek et al., 2010; Plotnik et al., 2005). Therefore, in the following paragraphs, we discuss explanations for the increased gait asymmetry caused by obstacle crossing and offer interpretations in terms of the positive effects of dopaminergic medication.

Obstacle crossing during walking increased gait asymmetry of crossing step (leading limb crossing step). Obstacle crossing requires that individuals perform adjustments during walking, necessitating rapid planning and execution of adaptive movements, and increasing motor demands (Snijders et al., 2010), which seems to exacerbate gait asymmetry. Obstacle avoidance involves complex circuitry of both central nervous system such as the parietal and motor cortex, the lateral cerebellum and pontine gray nuclei (Snijders et al., 2010), and peripheral nervous system such as sensory receptors, muscles, peripheral nerves, and joints, which appear to be more susceptible to sudden interference. For example, obstacle avoidance requires a more conservative and cautious strategy characterized by reduced velocity, shortened step length, and larger step width (Galna et al., 2009; Pieruccini-Faria et al., 2006; Vitório et al., 2013; Vitório et al., 2010). The combination of consciously controlling walking and deliberately avoiding obstacles may well outweigh the available resources, causing these adjustments and increasing gait asymmetry. Older individuals already present deficits in this circuitry, mainly in peripheral structures (Seidler et al., 2010), possibly causing asymmetry in complex walking such as obstacle crossing. These deficits are aggravated by PD that affects the basal ganglia, requiring greater compensatory involvement from other parts of the brain during walking (Berardelli, Rothwell, Thompson, \& Hallett, 2010). In addition, individuals with PD have a progressive difference in striatal uptake between the cerebral hemispheres in both the caudate and putamen nuclei and in the corticobasal ganglia-thalamic circuitry (Booij et al., 1997; Johnson-Frey, 2004; Kaasinen et al., 2001; Middleton \& Strick, 2000), which seems to increase gait asymmetry during challenging tasks. Individuals with PD present particular impairment when switching motor tasks, requiring subjects to make corrective steps instead of walking straight (Snijders et al., 2010), mainly during obstacle avoidance. One possible explanation is that the basal ganglia is important for set-dependent adaptation of movement patterns for changes in conditions, indicating that people with PD have inflexible control (Cools, Barker, Sahakian, \& Robbins, 2003), which is aggravated by sensory and perceptual deficits (Q. J. Almeida et al., 2005).

Dopaminergic medication depletion increased gait asymmetry in individuals with PD, mainly during obstacle crossing (see medication by walking by limb interaction). Previous studies have indicated that levodopa is efficient at improving gait asymmetry in unobstructed walking (Plotnik et al., 2005), and furthermore, under dopaminergic medication, individuals with PD seem to present similar asymmetry to neurologically healthy individuals. The effect of medication intake on gait asymmetry is consistent with its effect on gait rhythmicity (Hausdorff et al., 2003), which suggests that dopamine levels in people with PD directly influence gait asymmetry. The effects of dopaminergic medication demonstrated a delayed onset, shorter duration and similar magnitude on the most-affected side compared with the least-affected side (Kumar et al., 2003). Due to the prolonged use of medication or increase in dopaminergic 
TABLE 4. Summary of $p$ values and effect size (in brackets) of main effect and factor interactions for comparison between the control group and the PD group in the ON medication state (first part) and the PD group in the ON and OFF medication state (second part)

\begin{tabular}{|c|c|c|c|c|c|c|c|c|}
\hline & & \multicolumn{3}{|c|}{ Main effects } & \multicolumn{4}{|c|}{ Interactions } \\
\hline & & Group & Walking & Limb & $\begin{array}{l}\text { Group } \times \\
\text { Walking }\end{array}$ & $\underset{\text { Limb }}{\text { Group }} \times$ & $\begin{array}{l}\text { Walking } \times \\
\text { Limb }\end{array}$ & $\begin{array}{c}\text { Group } \times \text { Walking } \times \\
\text { Limb }\end{array}$ \\
\hline \multicolumn{9}{|c|}{ DP group ON state $\times$ Control group } \\
\hline Step length & Mean & $.04(.44)$ & $.04(.19)$ & $n s$ & $n s$ & $n s$ & $n s$ & $n s$ \\
\hline \multirow{3}{*}{ Step duration } & variability & $n s$ & $n s$ & $n s$ & $n s$ & $n s$ & $n s$ & $n s$ \\
\hline & Mean & $.08(.44)$ & $.001(.84)$ & $.01(.21)$ & $n s$ & $n s$ & $.03(.17)$ & $n s$ \\
\hline & variability & $n s$ & $.001(.51)$ & $n s$ & $n s$ & $n s$ & $n s$ & $n s$ \\
\hline \multirow[t]{2}{*}{ Step width } & Mean & $n s$ & $n s$ & $n s$ & $n s$ & $n s$ & $n s$ & $n s$ \\
\hline & variability & $n s$ & $n s$ & $n s$ & $n s$ & $n s$ & $n s$ & $n s$ \\
\hline Step velocity & Mean & $.03(.44)$ & $.001(.61)$ & $n s$ & $n s$ & $.04(.14)$ & $n s$ & $n s$ \\
\hline \multirow{3}{*}{ Limb swing } & variability & $n s$ & $n s$ & $n s$ & $n s$ & $n s$ & $n s$ & $n s$ \\
\hline & Mean & $n s$ & $.001(.89)$ & $.001(.36)$ & $n s$ & $n s$ & $n s$ & $n s$ \\
\hline & variability & $n s$ & $.03(.17)$ & $n s$ & $n s$ & $n s$ & $n s$ & $n s$ \\
\hline \multirow[t]{3}{*}{ Double support } & Mean & $n s$ & $.001(.91)$ & $.001(.38)$ & $n s$ & $n s$ & $n s$ & $n s$ \\
\hline & variability & $n s$ & $.01(.21)$ & $n s$ & $n s$ & $n s$ & $n s$ & $n s$ \\
\hline & & Med. & Walking & Limb & $\begin{array}{l}\text { Med. } \times \\
\text { Walking }\end{array}$ & $\begin{array}{l}\text { Med. } \times \\
\text { Limb }\end{array}$ & $\begin{array}{c}\text { Walking } \times \\
\text { Limb }\end{array}$ & $\begin{array}{c}\text { Med. } \times \text { Walking } \times \\
\text { Limb }\end{array}$ \\
\hline \multicolumn{9}{|c|}{ PD group ON state $\times$ PD group OFF state } \\
\hline \multirow[t]{2}{*}{ Step length } & Mean & $.03(.31)$ & $.03(.35)$ & $n s$ & $n s$ & $.04(.29)$ & $n s$ & $n s$ \\
\hline & variability & $.05(.27)$ & ns & $n s$ & $.004(.51)$ & $n s$ & $n s$ & $n s$ \\
\hline \multirow[t]{2}{*}{ Step duration } & Mean & $n s$ & $.001(.86)$ & $n s$ & $n s$ & $.003(.54)$ & $n s$ & $.002(.55)$ \\
\hline & variability & $n s$ & $.001(.70)$ & $n s$ & $n s$ & $n s$ & $n s$ & $n s$ \\
\hline \multirow[t]{2}{*}{ Step width } & Mean & $n s$ & $n s$ & $n s$ & $n s$ & $n s$ & $n s$ & $n s$ \\
\hline & variability & $n s$ & $n s$ & $n s$ & $n s$ & $n s$ & $n s$ & $.001(.73)$ \\
\hline \multirow[t]{2}{*}{ Step velocity } & Mean & $.02(.34)$ & $.003(.55)$ & $n s$ & $n s$ & $n s$ & $n s$ & $n s$ \\
\hline & variability & $n s$ & $n s$ & $n s$ & $n s$ & $n s$ & $n s$ & $n s$ \\
\hline \multirow[t]{2}{*}{ Limb swing } & Mean & $.01(.40)$ & $.001(.91)$ & $.03(.31)$ & $n s$ & $n s$ & $n s$ & $n s$ \\
\hline & variability & $n s$ & $.002(.58)$ & $n s$ & $n s$ & $n s$ & $n s$ & $n s$ \\
\hline \multirow[t]{2}{*}{ Double support } & Mean & $.01(.39)$ & $.001(.92)$ & $.04(.30)$ & $n s$ & $n s$ & $n s$ & $n s$ \\
\hline & variability & $n s$ & $.02(.38)$ & $n s$ & $.03(.32)$ & $n s$ & $n s$ & $n s$ \\
\hline
\end{tabular}

Med. = dopaminergic medication; $n s=$ not significant; $\mathrm{PD}=$ Parkinson's disease.

cell loss, the effects of medication become less efficient with disease progression (Katzenschlager \& Lees, 2002), which appears to increase the asymmetry (Barbieri et al., 2016). These findings may suggest that gait asymmetry increases proportionally with dopaminergic depletion, which impairs the use of the most-affected limb, especially to cross an obstacle, and coincides with postural instability.

Obstacle avoidance during walking seems to exacerbate the effects of medication and provide evidence of mechanical body control during this task. The lack of dopaminergic
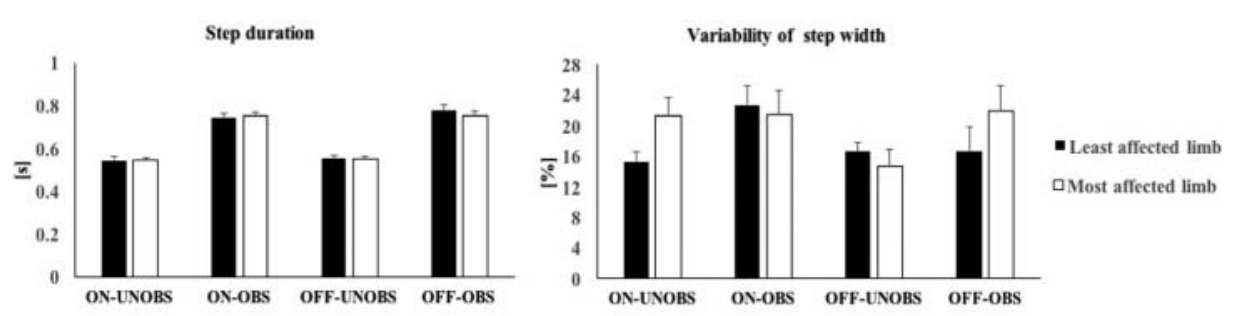

FIGURE 2. Medication by walking by limb interaction for (A) step duration and (b) variability of step width. 
medication effects in the OFF state in individuals with PD causes higher gait deficits, such as asymmetry, increasing the possibility of tripping or falling, mainly during obstacle avoidance, which requires more balance and stability and more mechanical adjustments to perform the task. The efficiency of dopaminergic medication during obstacle avoidance seems to reduce the asymmetric activity in the basal ganglia circuitry, indicating that asymmetry is a control problem (Beretta et al., 2015) and the mechanical control may be improved. In addition, the increase in variability of step width under dopaminergic medication for leastaffected limb seems a strategy to facilitate the focusing function of the basal ganglia (Bestmann, Ruge, Rothwel, \& Galea, 2015), improving motor flexibility-action reprogramming (Hausdorff et al., 2003), and, consequently, motor adjustments and mediolateral balance during the task. Therefore, the deficits and increase variability of mostaffected limb could be compensated.

\section{Conclusions}

In conclusion, obstacle crossing during walking increased gait asymmetry of crossing step in individuals with PD and, interestingly, in neurologically healthy individuals. However, dopaminergic medication decreased the gait asymmetry, especially during obstacle avoidance while walking. The findings provide a basis for considering that obstacle avoidance may well outweigh the available resources, increasing gait asymmetry. Future researchers should evaluate the effects of obstacle crossing while walking on gait asymmetry during the phase of approaching (two or three steps before obstacle) the obstacle.

\section{FUNDING}

The authors would like to thank FAPESP (\#2013/009254) for financial support.

\section{REFERENCES}

Almeida, O. P. (1998). Mini mental state examination and the diagnosis of dementia in Brazil. Arquivos de Neuro-Psiquiatria, 56, 605-612. http://dx.doi.org/10.1590/S0004-282X1998000400014

Almeida, Q. J., Frank, J. S., Roy, E. A., Jenkins, M. E., Spaulding, S., Patla, A. E., \& Jog, M. S. (2005). An evaluation of sensorimotor integration during locomotion toward a target in Parkinson's disease. Neuroscience, 134, 283-293. http://dx.doi. org/10.1016/j.neuroscience.2005.02.050

Baltadjieva, R., Giladi, N., Gruendlinger, L., Peretz, C., \& Hausdorff, J. M. (2006). Marked alterations in the gait timing and rhythmicity of patients with de novo Parkinson's disease. The European journal of neuroscience, 24, 1815-1820. http:// dx.doi.org/10.1111/j.1460-9568.2006.05033.x

Barbieri, F. A., Polastri, P. F., Baptista, A. M., Lirani-Silva, E., Simieli, L., Orcioli-Silva, D., ... Gobbi L. T. B. (2016). Effects of disease severity and medication state on postural control asymmetry during challenging postural tasks in individuals with Parkinson's disease. Human Movement Science, 46, 96103. http://dx.doi.org/10.1016/j.humov.2015.12.009

Berardelli, A., Rothwell, J. C., Thompson, P. D., \& Hallett, M. (2010). Pathophysiology of bradykinesia in Parkinson's disease. Brain, 124, 2131-2146. http://dx.doi.org/10.1093/brain/124.11.2131

Beretta, V.S., Gobbi, L. T. B., Lirani-Silva, E., Simieli, L., OrcioliSilva, D., \& Barbieri, F. A. (2015). Challenging postural tasks increase asymmetry in patients with Parkinson's disease. PLoS One, 9, e0137722. http://dx.doi.org/10.1371/journal.pone.0137722

Bestmann, S., Ruge, D., Rothwel, J., \& Galea, J. M. (2015). The role of dopamine in motor flexibility. Journal of Cognition and Neuroscience, 27, 365-376. http://dx.doi.org/10.1162/jocn_a_00706

Booij, J., Tissingh, G., Boer, G. J., Speelman, J. D., Stoof, J. C., Janssen, A. G., ... van Royen, E. A. (1997). FP-CIT SPECT shows a pronounced decline of striatal dopamine transporter labelling in early and advanced Parkinson's disease. Journal of neurology, neurosurgery, and psychiatry, 62, 133-140. http:// dx.doi.org/10.1136/jnnp.62.2.133

Chou, L., Kaufmann, K. R., Brey, R. H., \& Draganich, L. F. (2001). Motion of the whole body's center of mass when stepping over obstacles of different heights. Gait \& Posture, 13, 17-26. http://dx.doi.org/10.1016/S0966-6362(00)00087-4

Cools, R., Barker, R., Sahakian, B., \& Robbins, T. (2003). L-dopa medication remediates cognitive inflexibility, but increases impulsivity in patients with Parkinson's disease. Neuropsychology, 41, 1431-1444. http://dx.doi.org/10.1016/S0028-3932(03)00117-9

Fahn, S., \& Elton, R. (1987). Development comitee members of the UPDRS. The unified Parkinson's disease rating scale. In S. Fahn, C. D. Marsden, D. B. Calne, \& M. Goldstein (Eds.), Recent developments in Parkinson's disease (pp. 153-163). Florham Park, NJ: McMellam Health Care Information. http:// dx.doi.org/10.1002/mds.10473

Frazzitta, G., Pezzoli, G., Bertotti, G., \& Maestri, R. (2013). Asymmetry and freezing of gait in parkinsonian patients. Journal of Neurology, 260, 71-76. http://dx.doi.org/10.1007/ s00415-012-6585-4

Galna, B., Peters, A., Murphy, A. T., \& Morris, M. E. (2009). Obstacle crossing deficits in older adults: A systematic review. Gait \& Posture, 30, 270-275. http://dx.doi.org/10.1016/j. gaitpost.2009.05.022

Gibb, W. R., \& Lees, A. J. (1988). The relevance of the Lewy body to the pathogenesis of idiopathic Parkinson's disease. Journal of Neurology, Neurosurgery, and Psychiatry, 51, 745752. http://dx.doi.org/10.1136/jnnp.51.6.745

Hausdorff, J. M., Rios, D. A., \& Edelberg, H. K. (2001). Gait variability and fall risk in community-living older adults: A 1-year prospective study. Archives of physical medicine and rehabilitation, 82, 1050-1056. http://dx.doi.org/10.1053/apmr.2001.24893

Hausdorff, J. M., Schaafsma, J. D., Balash, Y., Bartels, A. L., Gurevich, T., \& Giladi, N. (2003). Impaired regulation of stride variability in Parkinson's disease subjects with freezing of gait. Experimental brain research, 149, 187-194. http://dx.doi.org/ 10.1007/s00221-002-1354-8

Herzog, W., Nigg, B. M., Read, L. J., \& Olsson, E. (1989). Asymmetries in ground reaction force patterns in normal human gait. Medicine and science in sports and exercise, 21, 110-114. http://dx.doi.org/10.1016/S0966-6362(96)01083-1

Hoehn, M. M., \& Yahr, M. D. (1967). Parkinsonism: Onset, progression and mortality. Neurology, 17, 427-442. http://dx.doi. org/10.1212/WNL.17.5.427:1526-632X

Johnson-Frey, S. H. (2004). The neural bases of complex tool use in humans. Trends in cognitive sciences, $8,71-78$. http://dx.doi. org/10.1016/j.tics.2003.12.002

Kaasinen, V., Nurmi, E., Bergman, J., Eskola, O., Solin, O., Sonninen, P., \& Rinne, J. O. (2001). Personality traits and brain dopaminergic function in Parkinson's disease. 
Proceedings of the National Academy of Sciences of the United States of America, 98, 13272-13277. http://dx.doi. org/10.1073/pnas.231313198

Katzenschlager, R., \& Lees, A. J. (2002). Treatment of Parkinson's disease: Levodopa as the first choice. Journal of neurology, 249, 19-24. http://dx.doi.org/10.1007/s00415-0021204-4

Kumar, A., Mann, S., Sossi, V., Ruth, T. J., Stoessl, A. J., Schulzer, M., \& Lee, C. S. (2003). [11C]DTBZ-PET correlates of levodopa responses in asymmetric Parkinson's disease. Brain, 126, 2648-2655. http://dx.doi.org/10.1093/brain/awg270

Lewek, M. D., Poole, R., Johnson, J., Halawa, O., \& Huang, X. (2010). Arm swing magnitude and asymmetry during gait in the early stages of Parkinson's disease. Gait \& Posture, 31, 256260. http://dx.doi.org/10.1016/j.gaitpost.2009.10.013

Middleton, F. A., \& Strick, P. L. (2000). Basal ganglia and cerebellar loops: Motor and cognitive circuits. Brain Research: Brain Research Reviews, 31, 236-250. http://dx.doi.org/ 10.1016/S0165-0173(99)00040-5

Nanhoe-Mahabier, W., Snijders, A. H., Delval, A., Weerdesteyn, V., Duysens, J., Overeem, S., \& Bloem, B. R. (2011). Walking patterns in Parkinson's disease with and without freezing of gait. Neuroscience, 182, 217-224. http://dx.doi.org/10.1016/j. neuroscience.2011.02.061

Patla, A. E., \& Prentice, S. D. (1995). The role of active forces and intersegmental dynamics in the control of leg trajectory over obstacles during locomotion in humans. Experimental Brain Research, 106, 499-504. http://dx.doi.org/10.1007/BF00231074

Pieruccini-Faria, F., Menuchi, M. R. T. P., Vitório, R., Gobbi, L. T. B., Stella, F., \& Gobbi, S. (2006). Kinematic parameters for gait with obstacles among elderly patients with Parkinson's disease, with and without levodopa: A pilot study. Brazilian Journal of Physical Therapy, 10, 233-239. http://dx.doi.org/ 10.1590/S1413-35552006000200015

Plotnik, M., Giladi, N., Balash, Y., Peretz, C., \& Hausdorff, J. M. (2005). Is freezing of gait in Parkinson's disease related to asymmetric motor function? Annals of Neurology, 57, 656-663. http://dx.doi.org/10.1002/ana.20452

Plotnik, M., Giladi, N., \& Hausdorff, J. M. (2009). Bilateral coordination of gait and Parkinson's disease: The effects of dual tasking. Journal of Neurology Neurosurgery \& Psychiatry, 80 347-350. http://dx.doi.org/10.1136/jnnp.2008.15736

Sadeghi, H., Allard, P., Prince, F., \& Labelle, H. (2000). Symmetry and limb dominance in able-bodied gait: A review. Gait \& Posture, 12, 34-45. http://dx.doi.org/10.1016/S0966-6362(00) 00070-9

Seidler, R. D., Bernard, J. A., Burutolu, T. B., Fling, B. W., Gordon, M. T., Gwin, J. T., ... Lipps, D. B. (2010). Motor control and aging: links to age-related brain structural, functional, and biochemical effects. Neuroscience \& Biobehavioral Reviews, 34, 721-733. http://dx.doi.org/10.1016/j. neubiorev.2009.10.005

Snijders, A. H., Weerdesteyn, V., Hagen, Y. J., Duysens, J., Giladi, N., \& Bloem, B. R. (2010). Obstacle avoidance to elicit freezing of gait during treadmill walking. Movement Disorders, 25, 57-63. http://dx.doi.org/10.1002/mds.22894

Stewart, K. C., Fernandez, H. H., Okun, M. S., Rodriguez, R. L., Jacobson, C. E., \& Hass, C. J. (2009). Side onset influences motor impairments in Parkinson disease. Parkinsonism \& Related Disorders, 15, 781-783. http://dx.doi.org/10.1002/ mds. 23429

Tomlinson, C. L., Stowe, R., Patel, S., Rick, C., Gray, R., \& Clarke, C. E. (2010). Systematic review of levodopa dose equivalency reporting in Parkinson's disease. Movement disorders, 25, 2649-2653. http://dx.doi.org/10.1016/j. parkreldis.2009.02.001

Vitório, R., Lirani-Silva, E., Barbieri, F. A., Raile, V., Stella, F., \& Gobbi, L. T. (2013). Influence of visual feedback sampling on obstacle crossing behavior in people with Parkinson's disease. Gait \& Posture, 38, 330-334. http://dx.doi.org/10.1016/j. gaitpost.2012.12.019

Vitório, R., Pieruccini-Faria, F., Stella, F., Gobbi, S., \& Gobbi, L. T. B. (2010). Effects of obstacle height on obstacle crossing in mild Parkinson's disease. Gait \& Posture, 31, 143-146. http:// dx.doi.org/10.1016/j.gaitpost.2009.09.011

Received June 9, 2016

Revised September 28, 2016

Accepted November 30, 2016 